\title{
Aprendizagem de Matemática em Ambientes Virtuais: o ROODA Exata como Possibilidade
}

\author{
Márcia Rodrigues Notare; PGIE/UFRGS; marcia.notare@ gmail.com \\ Patricia Alejandra Behar; PGIE/UFRGS; pbehar@terra.com.br
}

Resumo: Este artigo discute a aprendizagem da Matemática em ambientes virtuais de aprendizagem. Sabe-se que o foco central da aprendizagem on-line é a comunicação mediada pelas ferramentas de interação disponíveis nestes ambientes. Contudo, a comunicação matemática ainda não é satisfatória, pois os ambientes virtuais de aprendizagem não oferecem o recurso de edição de expressões científicas. Assim, este artigo apresenta o editor científico ROODA Exata e sua utilização em uma turma de Cálculo Diferencial.

Palavras-Chave: ambientes virtuais de aprendizagem; comunicação matemática; aprendizagem de matemática

\section{The learning of Mathematics in virtual environments: the ROODA Exata as possible}

\begin{abstract}
The present article aims to discuss the learning of Mathematics in virtual learning environments. It is known that the main focus of online learning is communication mediated by interaction tools available in virtual environments; however, mathematical communication is so far insufficient because virtual learning environments do not offer edition resources for scientific expressions. Thus, this article presents the scientific editor ROODA Exata and its use by a group in a Differential Calculus discipline.
\end{abstract}

Keywords: learnig environment; mathematical communication; learning of mathematics

\section{Introdução}

A aprendizagem de Matemática preocupa professores de todos os níveis educacionais. Não é de hoje que são observadas dificuldades de aprendizagem em Matemática, vivenciadas por alunos desde a educação básica até o nível superior. Os alunos, em sua maioria, entendem a Matemática como um conjunto de regras, métodos e fórmulas, que precisam ser memorizadas para solucionar listas intermináveis de exercícios repetitivos. Eles não compreendem a Matemática em sua verdadeira essência, com sua estrutura lógica e sua linguagem.

Os professores de Matemática, em sua maioria, têm consciência dessa realidade e sentem-se desconfortáveis com essa situação. Muitos reconhecem que os métodos tradicionais de ensino têm-se mostrado insuficientes para resolver o problema e sentemse desafiados a enfrentar e superar esta questão. Assim, é inevitável uma busca por alternativas metodológicas que favoreçam a compreensão da Matemática.

A Matemática pode ser entendida como uma forma de linguagem precisa, clara e objetiva, e sua compreensão implica, entre outros fatores, no domínio dessa linguagem. Assim, entender Matemática não significa efetuar cálculos corretamente, mas saber expressar-se corretamente através de sua linguagem. Desse modo, percebe-se que o 
processo de aprendizagem de Matemática precisa valorizar ações como comunicação e expressão, através de atividades que exijam a argumentação e justificativa, de modo a incentivar o aluno a refletir sobre suas ações e explicar seu raciocínio, tomando consciência de seus atos.

Paralelamente, percebe-se que as tecnologias da informação e comunicação estão, cada vez mais, sendo utilizadas em cursos de graduação, tanto para viabilizar cursos a distância, como para apoiar cursos presenciais. Sua utilização, através de ferramentas de comunicação e interação, como fórum de discussão, sala de bate-papo, lista de discussão, mensagens instantâneas, entre outros, vem proporcionando momentos de aprendizagem extra-classe, em que ocorrem debates e discussões, que promovem uma construção coletiva do conhecimento.

Assim, viu-se como uma alternativa metodológica para a Educação Matemática, a utilização desses recursos tecnológicos. As tecnologias da informação e comunicação podem criar uma metodologia de ensino e aprendizagem que promove a participação, através de problemas que podem ser discutidos e resolvidos em conjunto, de modo a construir o conhecimento matemático relacionado aos conceitos estudados.

Contudo, essas trocas realizadas no meio virtual ainda dependem fortemente da comunicação escrita. Para se comunicar em Matemática, é indispensável a utilização de símbolos e fórmulas, que servem para facilitar a comunicação e expressão matemática, tornando-a precisa e objetiva. Os ambientes virtuais de aprendizagem disponíveis até o momento ainda não apresentam soluções eficientes para a questão da comunicação matemática on-line.

Visando oferecer alternativas de solução para o problema da comunicação matemática on-line, este trabalho apresenta o editor científico ROODA Exata. $\mathrm{O}$ ROODA Exata foi pensado de modo a atender às necessidades essenciais que viabilizam a comunicação matemática on-line, contendo os símbolos e estruturas mais utilizados na área.

Para avaliar seu funcionamento e sua usabilidade, foi utilizado o ambiente virtual de aprendizagem ROODA, como um meio de apoio extra-classe em turmas de Cálculo Diferencial, onde o ROODA Exata foi utilizado sempre que necessário para a edição e expressões matemáticas.

\section{A Construção do Conhecimento Matemático}

A teoria do desenvolvimento cognitivo de Piaget defende a idéia de que a ação é a força propulsora do desenvolvimento humano (Piaget, 1983). Para este autor, a aprendizagem ocorre a partir das ações do sujeito sobre o meio. Esta aprendizagem ocorre porque o sujeito vive em busca de um equilíbrio dinâmico com seu ambiente. Sempre que este equilíbrio é perturbado pela presença de uma nova situação, ainda não vivenciada pelo sujeito, este entra em conflito cognitivo. É na busca pelo re-equilíbrio, que o sujeito constrói novas estruturas cognitivas e avança no seu conhecimento. Nesta perspectiva, tudo acontece pela ação do sujeito, pois é através dela que se constroem as estruturas do conhecimento ou capacidades de conhecer.

O mesmo ocorre com a construção do conhecimento matemático: a cada novo problema matemático vivenciado, o sujeito é perturbado e desafiado a superá-lo. Para resolver o problema, é necessária a construção de novas estruturas que permitam dar conta da situação enfrentada, rever os conceitos já elaborados e tentar reconstruí-los e enriquece-los, de forma a solucionar o problema apresentado. Se o aluno não vive o problema como uma contradição interna, não sentirá necessidade de construir algo novo para resolver tal problema. Este processo é contínuo e são justamente estes desafios que 
promovem o desenvolvimento do ser humano, bem como a construção do conhecimento matemático.

Sabe-se que há um sucesso aparente dos alunos na resolução de problemas. Isto porque, geralmente, os mesmos aprenderam, em suas aulas de Matemática escolar, apenas rituais e receitas, como se houvesse um roteiro ou um modelo a ser seguido na resolução de um problema. Dessa forma, o que ocorre é a aprendizagem de um conjunto de procedimentos padrões, que possibilitam a resolução de uma classe de problemas limitada. Esse processo está longe do verdadeiro "fazer matemática", que exige habilidades como conjecturar, testar, intuir, deduzir, generalizar - coordenar ações e retirar dessas coordenações novas coordenações, por abstrações refletidas; os alunos adquirem apenas a capacidade de efetuar cálculos, sem compreendê-los.

Piaget (1978) afirma que a ação precede a conceituação. Muitas vezes, um sujeito realiza uma determinada ação, impulsionado por determinado objetivo, e obtêm sucesso em sua realização. Entretanto, não consegue descrever os caminhos que o levaram a este sucesso, o que mostra a ausência de compreensão dos conceitos envolvidos em seus atos. Situações como esta são freqüentemente observadas nas aulas de Matemática. A valorização de métodos e roteiros para a resolução de problemas faz com que alunos resolvam os problemas apresentados, sem a necessidade de uma verdadeira compreensão dos conceitos matemáticos envolvidos nestes procedimentos; sem agir sobre as coordenações de suas ações e retirar delas qualidades que lhes são próprias.

A representação tem um papel importante na Matemática, uma vez que os símbolos são indispensáveis em seu desenvolvimento. Uma representação simbólica é escrita externamente com o objetivo de permitir a comunicação sobre um conceito de forma fácil e precisa. Uma representação mental, por outro lado, refere-se ao esquema interno de cada pessoa, que o utiliza para agir com o mundo externo. As representações mentais são criadas na mente do indivíduo sobre um sistema de representações concretas. O sucesso em Matemática requer uma rica representação mental dos conceitos matemáticos, ou seja, a criação de vários componentes mentais para um mesmo objeto matemático (leis, gráficos, tabelas, etc.). Tal riqueza permite uma maior flexibilidade de pensamento no processo de resolução de problemas.

Outra etapa importante no "fazer matemática" é a abstração. A capacidade de abstrair conduz ao pensamento matemático avançado (na verdade, a abstração conduz a todo e qualquer conhecimento lógico ou matemático, desde os níveis mais elementares até a matemática mais avançada). Dois processos estão envolvidos na abstração: a generalização e a síntese.

Para Dreyfus (1991), generalizar significa derivar de casos particulares propriedades comuns, para expandir o domínio de validação das mesmas. Isso exige uma transição dos casos particulares para o caso geral. Muitas vezes, as exigências cognitivas no processo de generalização são consideráveis. Por outro lado, o processo de síntese consiste em compor partes em um todo, sendo que este todo significa mais que a soma das partes. Para tal, é necessário estabelecer conexões, relações entre conceitos, compondo um todo inter-relacionado e coerente.

Estes processos envolvem as diferentes formas de abstração definidas por Piaget (1995): abstração empírica e abstração reflexionante. No início do processo de generalização, é preciso extrair propriedades dos objetos (patamar da ação e representação), comparar os diferentes objetos matemáticos, identificando propriedades comuns (patamar das comparações), para finalmente fazer a transição dos casos particulares para o geral (patamar das reflexões-sobre-reflexões). 


\subsection{O Papel da Comunicação e Expressão na Aprendizagem de Matemática}

Compreender Matemática não se resume a manipular técnicas operatórias, de forma mecânica, nem memorizar fórmulas, regras e propriedades. Compreender Matemática é entender o que se lê e escreve, buscando significado para isso. Em outras palavras, para entendê-la, não basta saber ler, escrever e contar; é preciso saber expressar-se, pois a expressão auxilia na concretização do pensamento. Quando um sujeito consegue se expressar, argumentando sobre determinado conceito ou assunto, está em um nível mais elevado de compreensão, se comparado àquele sujeito que apenas resolve numericamente um problema, através da utilização de uma fórmula, regra ou equação. Assim, na aprendizagem de Matemática, torna-se importante incentivar o aluno a pensar e expressar o que pensa, seja falando ou escrevendo, de modo a justificar suas idéias e refletir sobre suas concepções. Se um sujeito consegue expressar-se sobre determinado assunto, há indícios de que o mesmo está em atividade reflexiva, ou seja, em processo de coordenação do pensamento (Piaget, 1995).

A comunicação em Matemática é realizada, basicamente, de forma escrita. As línguas naturais faladas podem até descrever objetos matemáticos e suas propriedades, mas o simbolismo permite descrever a mesma propriedade de forma direta, rápida e precisa, ou seja, quando as propriedades estruturais tornam-se mais complexas, sua descrição torna-se difícil de ser falada e compreendida sem a utilização de símbolos. Assim, o simbolismo apresenta-se como um simplificador e facilitador da Matemática, permitindo clareza e rapidez na resolução de problemas e expressão de idéias.

Muitas vezes, percebe-se que os alunos resolvem determinados problemas e equações corretamente, mas não conseguem justificar o procedimento utilizado ou argumentar sobre o que foi feito, como foi feito e porque foi feito. Observa-se, nestes casos, uma situação de "saber fazer", mas "sem compreender". Estes alunos sabem resolver o problema, encontram uma solução para o mesmo, mas não compreendem o que realmente fizeram e, muitas vezes, nem mesmo dão uma interpretação para a solução encontrada. Tais situações dão indícios de que são realizados operações e cálculos de forma mecânica, sem significado, portanto, sem conceituação. Para chegar ao nível da compreensão, é necessário atingir níveis mais elevados de abstração, o que acontece mediante tomadas de consciência, especialmente, mediante abstração refletida (abstração reflexionante com tomada de consciência).

Assim, pode-se perceber que a representação e a abstração são processos complementares. Por um lado, um conceito matemático pode ser abstraído de várias representações e, por outro lado, representações são sempre representações de algum conceito abstrato, melhor dito, formal. Quando várias representações de um mesmo objeto são consideradas simultaneamente, a relação com o conceito abstrato formal torna-se presente e importante. Enfim, compreende-se que a aprendizagem de Matemática é um processo que envolve, entre outras características, o exercício da expressão, argumentação, justificativa, em paralelo com a capacidade de reconhecer e trabalhar com as diferentes representações.

\section{A Comunicação Matemática a Distância: O ROODA Exata como uma Possibilidade}

Como visto anteriormente, para aprender Matemática é importante desenvolver as capacidades de expressão, argumentação e justificativa. Assim, visualizou-se nos ambientes virtuais de aprendizagem uma alternativa para incentivar e desenvolver estas habilidades. Isto porque, tais ambientes proporcionam a realização de debates em torno da resolução de problemas, que incentivam e favorecem o exercício da argumentação e justificativa. 
As trocas que ocorrem nesses ambientes são viabilizadas por ferramentas de interação, predominantemente escritas, tais como fórum de discussão, bate-papo, mensagens instantâneas, entre outras. Assim, para que a comunicação matemática ocorra, de forma intuitiva e rápida, torna-se necessária a utilização dos símbolos que descrevam as expressões matemáticas. Entretanto, tais ferramentas ainda não oferecem recursos para a edição de notação matemática, sem a necessidade de utilização de arquivos anexos ou linguagens de formatação.

Assim, foi projetado e desenvolvido o ROODA Exata, um editor científico integrado ao ambiente ROODA ${ }^{1}$, pensado de modo a não necessitar da utilização de linguagens de formatação, para que sua utilização fosse transparente e intuitiva ao usuário. Desse modo, a interação no editor é realizada através de ícones e botões que permitem a inserção de símbolos e fórmulas através de um simples clique do mouse.

A estrutura do ROODA Exata foi organizada em três grandes categorias: símbolos, fórmulas e alfabeto grego, conforme mostra a Figura 1. A aba de símbolos contém os símbolos mais utilizados na comunicação e expressão matemática, tais como símbolos relacionais, operadores, símbolos lógicos, símbolos da teoria de conjuntos, conjuntos numéricos, somatório, produtório e integral, entre outros. A aba de fórmulas é constituída pelas principais fórmulas de Matemática, e foi elaborada para diminuir o esforço do usuário na comunicação, tornando-a mais rápida, uma vez que as fórmulas mais utilizadas podem ser inseridas diretamente com um simples clique. Finalmente, tem-se a aba do alfabeto grego, que contém o alfabeto grego maiúsculo e minúsculo, por ser amplamente utilizado na comunicação e expressão científica.
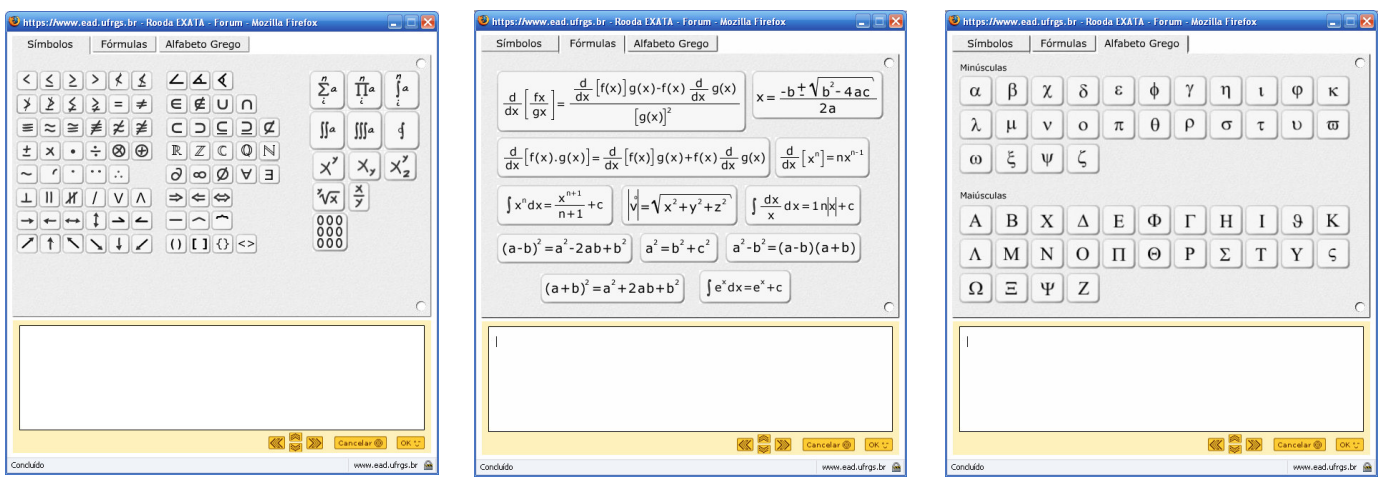

Figura 1 - Abas do editor ROODA Exata

Até o momento, o ROODA Exata encontra-se disponível nas ferramentas fórum de discussão e bate-papo e, para acessá-lo, basta um clique sobre o botão de acesso. As expressões matemáticas são construídas através dos botões do editor. Por exemplo, se o usuário deseja inserir a raiz quadrada de uma fração no texto, basta clicar sobre o botão $\sqrt[y]{x}$ e, em seguida, clicar sobre o botão $\frac{x}{y}$. Uma caixa de edição é aberta, que permite a inserção das variáveis desejadas. Assim, percebe-se que novas estruturas podem ser inseridas nas estruturas já criadas, permitindo a composição, por exemplo, de radicais com frações, como é possível observar na Figura 2. Isto revela o potencial do ROODA Exata na edição de expressões matemáticas com estruturas mais complexas.

\footnotetext{
${ }^{1} \mathrm{O}$ ambiente de aprendizagem ROODA disponibiliza recursos síncronos e assíncronos para interação e comunicação entre professores e alunos, centrado no usuário e de modo a valorizar o processo de cooperação. Encontra-se disponível em https://www.ead.ufrgs.br/rooda.
} 


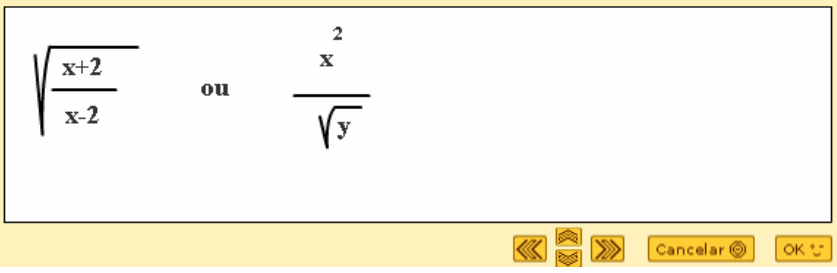

Figura 2 - Exemplo de edição de expressão matemática

\section{Utilização do ROODA Exata}

Para analisar a ferramenta desenvolvida, utilizou-se o ambiente virtual de aprendizagem ROODA como uma ferramenta de apoio às aulas presenciais de uma turma de Cálculo Diferencial, sendo o mesmo sugerido como um meio de comunicação e interação extraclasse, para trocas de informação, tira-dúvidas e resolução de problemas. A partir da participação dos alunos no ambiente, foram analisados a viabilidade de comunicação matemática a distância e o processo de aprendizagem, à luz da epistemologia genética de Piaget $(1977,1978,1995)$.

A turma contou, inicialmente, com trinta e cinco alunos matriculados. Destes, vinte e nove alunos cadastraram-se no ambiente ROODA para participar das atividades extra-classe e acompanharam a disciplina ao longo do semestre. As atividades foram propostas por meio da ferramenta fórum de discussão, e o editor científico ROODA Exata foi utilizado pela turma conforme a necessidade de edição de expressões matemáticas.

Foram realizadas análises a partir de diversos problemas propostos para a turma, em que se buscou analisar os processos cognitivos desencadeados ao longo dos debates ocorridos no ambiente. Contudo, apresenta-se aqui uma, das muitas situações ocorridas, com o objetivo de ilustrar a utilização do ROODA Exata e as análises realizadas a partir das contribuições dos alunos. O problema ilustrado na Figura 3 refere-se à aplicação do conceito de derivada em problemas de otimização. Para resolver o problema, é preciso interpretá-lo, equacioná-lo e finalmente resolve-lo. São problemas completos, que exigem uma compreensão de vários conceitos trabalhados ao longo do curso de Cálculo Diferencial.

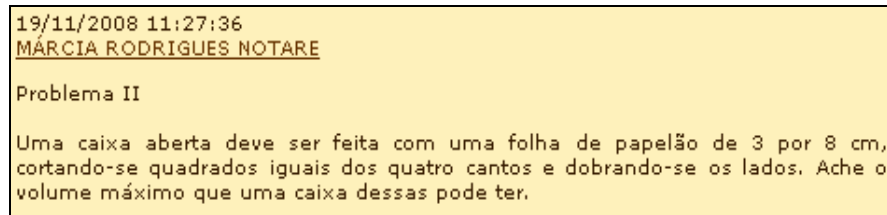

Figura 3 - Problema de otimização

Um grupo de alunos apresentou a solução para este problema, de forma detalhada, justificada e argumentada, revelando compreender o conceito de derivada e sua aplicação em problemas de otimização, como se pode observar na Figura 4. Percebe-se que o grupo, inicialmente, interpreta o problema e busca descreve-lo, de modo a identificar a variável independente dentro do contexto apresentado. Em seguida, apresentam uma equação que representa a situação ${ }^{2}$. É possível notar o nível de compreensão do grupo quando, ao encontrar as raízes da derivada, são capazes de excluir a raiz que esta fora do domínio do problema. Isto que revela, não apenas a aplicação mecânica de um procedimento, mas a compreensão das ações realizadas.

\footnotetext{
${ }^{2}$ Observa-se um pequeno erro no termo final da equação - em lugar de 36 seria 24x, mas certamente é um erro de digitação, pois mais adiante a derivada foi calculada corretamente.
} 
Certamente, se não houvesse compreensão, em pensamento, das ações realizadas pelo grupo (cálculos que estão sendo realizados), todas as raízes da derivada seriam consideradas na análise final, evidenciando uma aplicação mecânica de regras e procedimentos.

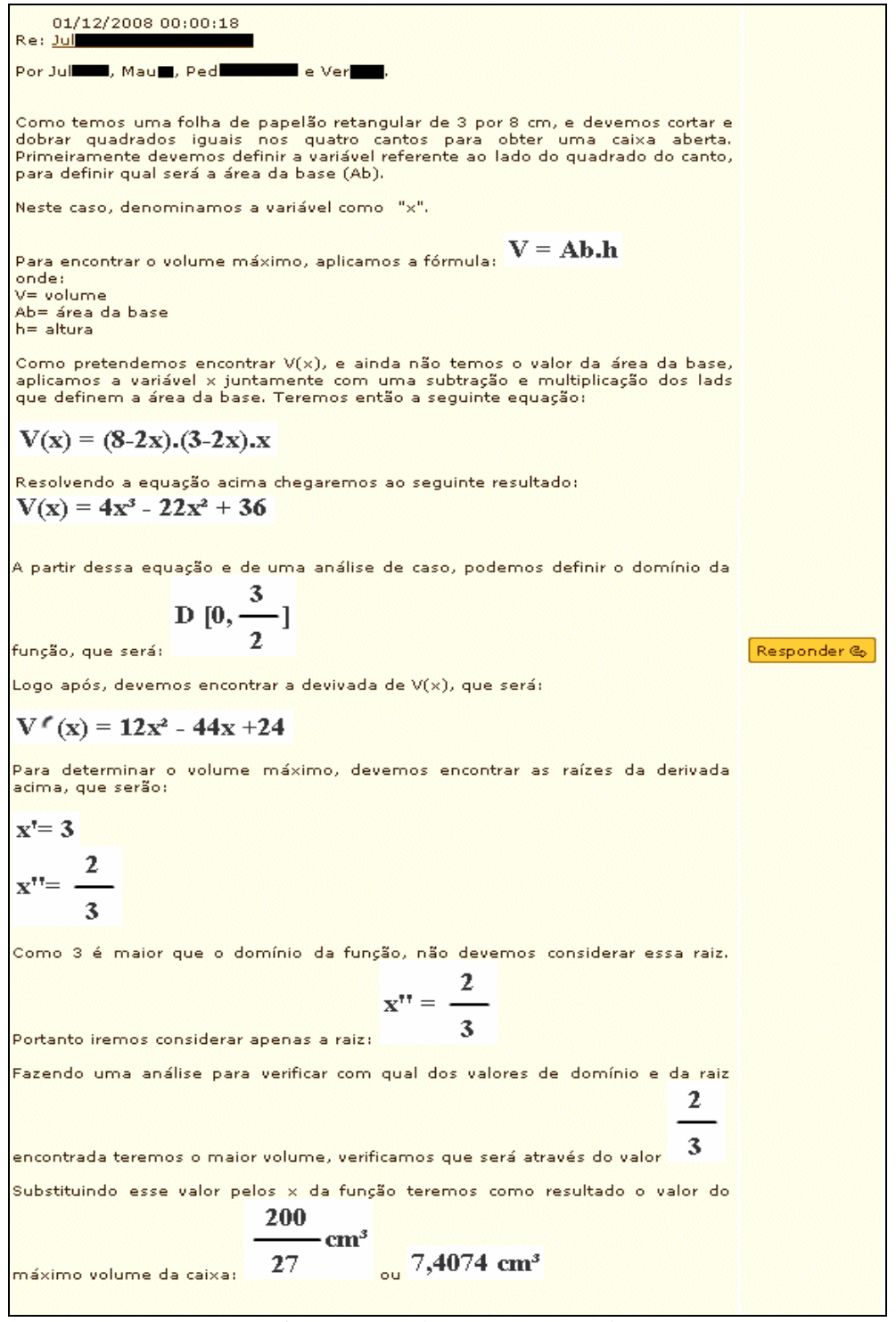

Figura 4 - Solução apresentada

Entretanto, a professora encaminha alguns questionamentos, com o objetivo de identificar o nível de compreensão do grupo acerca dos conceitos matemáticos envolvidos na solução do problema, conforme Figura 5. 


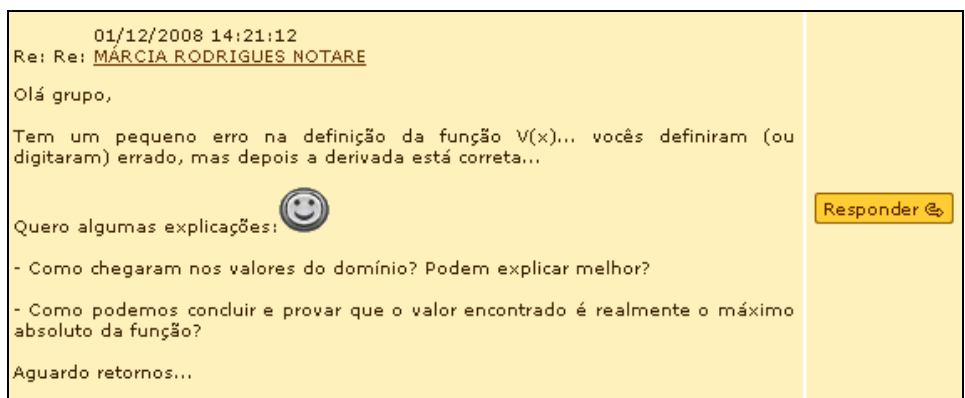

Figura 5 - Questionamentos feitos pela professora

A Figura 6 apresenta o retorno do grupo. Percebe-se que a identificação do domínio da função no contexto do problema apresentado está clara para o grupo, no momento em que afirmam "Como o menor lado do retângulo corresponde a $3 \mathrm{~cm}$, consideramos para o domínio o valor referente a metade deste lado". O grupo percebe que valores de x maiores que 3/2 não fazem sentido para o problema, pois não poderão ser cortados de todos os cantos do retângulo para a confecção da caixa. Isto revela uma compreensão da situação apresentada, e não uma aplicação de procedimentos mecânicos para encontrar valores extremos para qualquer valor de $x$. Ainda, na solução inicial, ficou omitido porque o volume máximo ocorreria para $x=2 / 3$. Então, o grupo foi capaz de relatar que os possíveis valores de máximo da função podem ocorrer nos extremos do intervalo ou nas raízes da derivada, ao verificar a imagem de $\mathrm{V}(x)$ para $x=0, x=2 / 3$ e $x=3 / 2$.

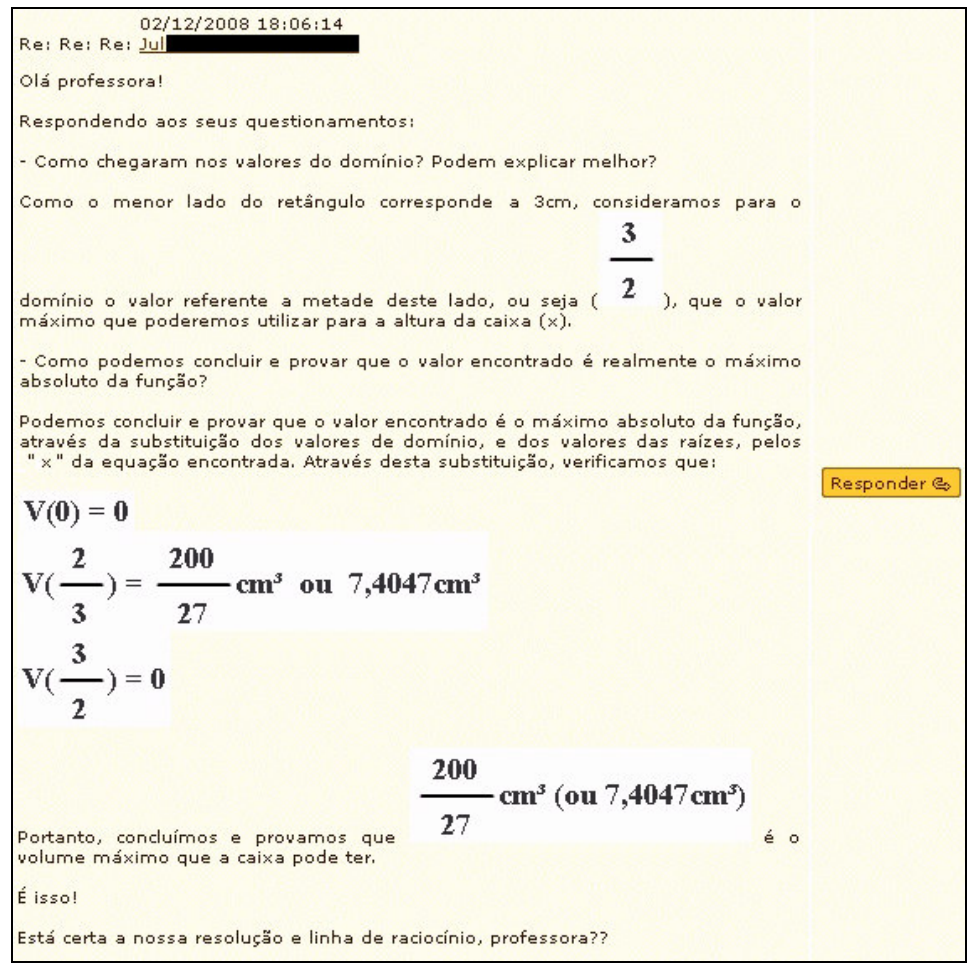

Figura 6 - Retorno do grupo

A resolução de problemas como este exige níveis elevados de abstração. Para estabelecer o domínio da função no problema apresentado, é preciso analisar a situação, estudar os casos extremos, ou seja, situações limites permitidas para a confecção da caixa. Isto exige abstrações reflexionantes, pois não podem se apoiar sobre observáveis, uma vez que o aluno não está manipulando o papelão, cortando quadrados de seus 
quatro cantos, nem mesmo confeccionando diversas caixas de modo a identificar as possíveis medidas para o tamanho do quadrado a ser recortado. São as coordenações das ações que permitem ao aluno chegar ao domínio da função; são as reflexões realizadas que levam à solução desta questão. Ainda, compreender que o volume máximo da caixa será dado a partir da derivada da função volume exige a compreensão do conceito de extremo absoluto de uma função, sua relação com a derivada e sua aplicação no contexto do problema apresentado. Percebe-se a relação entre diversos conceitos matemáticos sendo utilizados simultaneamente para a solução de um mesmo problema. Para que isso ocorra, é necessário que o aluno tenha tomado consciência destes conceitos, de modo a aplicá-los em diferentes situações-problema.

Muitos debates ocorreram ao longo do semestre no ambiente virtual. A utilização do ROODA possibilitou aos alunos assumirem uma postura mais ativa, em que foi necessário participar das discussões, elaborar soluções, refletir sobre os conceitos trabalhados, trabalhar em conjunto com os demais colegas, comparando soluções, corrigindo equívocos e organizando idéias. Assim, aqueles que se comprometeram seriamente com este trabalho, puderam avançar no seu conhecimento matemático.

Contudo, sentiu-se a necessidade de verificar a percepção dos alunos sobre as atividades realizadas no ROODA e sobre a utilização do editor científico ROODA Exata. Para isso, no final do semestre letivo, foi aplicado um questionário à turma. A partir das respostas da turma, verificou-se que o ROODA Exata se fez necessário para viabilizar a comunicação matemática on-line, como é possível observar em afirmações como: "O ROODA Exata foi uma ferramenta indispensável."; "O editor possibilita expressar radicais, racionalização, potências de forma simplificada. As imagens nele geradas facilitam o entendimento."; e "Ali estavam todas as fórmulas que foi preciso para responder as atividades.". Com relação às possíveis dificuldades de utilização da ferramenta, constatou-se que alguns alunos revelaram sentir dificuldades iniciais de utilização, mas que, com o tempo, foram superadas, conforme comentários selecionados a seguir: "A dificuldade foi apenas no primeiro impacto com a ferramenta, mas com a construção de mais fórmulas, percebe-se que é simples e útil para efetuar expressões."; "Sim, não tinha visto nada parecido na Internet antes. Mas é só questão de costume."; e "Começar a utilizar o ROODA Exata não é muito simples. Mas após um período certo de uso a ferramenta se torna bastante útil.". De fato, parece natural que um primeiro contato com a ferramenta ofereça uma certa dificuldade, até porque os alunos não estão habituados a editar expressões matemáticas rotineiramente. Contudo, percebe-se que, em pouco tempo, seu manuseio torna-se natural.

Os alunos também foram questionados sobre a metodologia adotada no semestre, que utilizou o ROODA como apoio às aulas presenciais. Seguem algumas respostas: "Sim, muito. Gostei muito da iniciativa da professora. As atividades ajudaram a ter mais comprometimento e a esclarecer dúvidas."; "Acho que ajuda a tirar algumas dúvidas que surgem quando se está estudando em casa."; "Sim, pela troca de informações."; "Sim, além de se comunicar com o professor também é possível se comunicar com os colegas.". Assim, percebe-se que alguns viram no ambiente uma oportunidade para tirar dúvidas, enquanto outros se sentiram mais comprometidos com os estudos e ainda, outros enfatizaram a troca de informações e a comunicação. Com isso, fica evidenciado que a percepção dos alunos acerca da metodologia adotada, que utiliza um ambiente virtual de aprendizagem como apoio às aulas presenciais, foi positiva. Mais do isso, pode-se criar um espaço de comunicação e aprendizagem que buscou valorizar a expressão e comunicação matemática, através de problemas que foram argumentados e justificados pela turma. 


\section{Considerações Finais}

Este trabalho apresentou as possibilidades de utilização das tecnologias da informação e comunicação no processo de aprendizagem de Matemática, viabilizadas pelo editor científico ROODA Exata. Mostrou-se a possibilidade de utilização de um ambiente virtual de aprendizagem como apoio a aulas presenciais, com o objetivo de incentivar os alunos a argumentar e justificar seus raciocínios, além de colaborar com os colegas na construção do conhecimento matemático.

É importante salientar que o sucesso em situações de ensino e aprendizagem de Matemática a distância, seja em modalidade presencial ou totalmente a distância, não está garantido pela simples utilização do editor científico ROODA Exata. Pensar em metodologias de utilização que valorizem a participação ativa do aluno, assim como repensar os papéis do professor e do aluno neste contexto, são fundamentais para que esse sucesso ocorra.

Além disso, a aprendizagem da Matemática é um processo que não envolve apenas a comunicação e expressão algébrica. $O$ trabalho com as diferentes representações de um mesmo objeto matemático é indispensável neste processo. Entretanto, o foco principal deste trabalho foi viabilizar a comunicação em Matemática, uma vez que a aprendizagem a distância é alicerçada pelas trocas ocorridas no meio virtual, trocas estas proporcionadas pela escrita.

\section{Referências Bibliográficas}

DREYFUS, Tommy. Advanced Mathematical Thinking Processes. In: Tall, David (Ed.), Advanced Mathematical Thinking. Norwell: Kluver Academic Publishers, 1991, p. $25-40$.

PIAGET, Jean. A Tomada de Consciência. São Paulo: Melhoramentos, Editora da Universidade de São Paulo, 1977.

PIAGET, Jean. A Epistemologia Genética. São Paulo: Abril Cultural, Coleção Os Pensadores, 1983.

PIAGET, Jean. Fazer e Compreender. São Paulo: Melhoramentos, Editora da Universidade de São Paulo, 1978.

PIAGET, Jean. Abstração Reflexionante. Porto Alegre: Artes Médicas, 1995. 